OPEN ACCESS

Edited by:

Yu-Qiang Ding,

Tongji University,

China

Reviewed by:

Chen Zhang,

Shanghai Mental Health Center (SMHC), China

Ole Köhler-Forsberg,

Aarhus University,

Denmark

${ }^{*}$ Correspondence:

Cunyan Li

zjjlcy@csu.edu.cn

Specialty section: This article was submitted to

Schizophrenia,

a section of the journal

Frontiers in Psychiatry

Received: 02 November 2018 Accepted: 25 March 2019

Published: 10 April 2019

Citation:

Liu Y, Tao H, Yang X, Huang $K$, Zhang $X$ and Li C (2019)

Decreased Serum Oxytocin and Increased Homocysteine in First-Episode Schizophrenia Patients.

Front. Psychiatry 10.217.

doi: 10.3389/fpsyt.2019.00217

\section{Decreased Serum Oxytocin and Increased Homocysteine in First-Episode Schizophrenia Patients}

\author{
Yong Liu ${ }^{1,2,3}$, Huai Tao ${ }^{4}$, Xiudeng Yang ${ }^{5}$, Kai Huang ${ }^{1,2,3}$, Xianghui Zhang ${ }^{1,2,3}$ and Cunyan Li ${ }^{6}$ \\ ${ }^{1}$ Department of Psychiatry, The Second Xiangya Hospital, Central South University, Changsha, China, ${ }^{2}$ China National \\ Clinical Research Center on Mental Disorders (Xiangya) and China National Technology Institute on Mental Disorders, \\ Changsha, China, ${ }^{3}$ Mental Health Institute of Central South University and Hunan Key Laboratory of Psychiatry and Mental \\ Health, Changsha, China, ${ }^{4}$ Department of Biochemistry and Molecular Biology, Hunan University of Chinese Medicine, \\ Changsha, China, ${ }^{5}$ Department of Laboratory Medicine, The First Affiliated Hospital of Shaoyang University, Shaoyang, \\ China, ${ }^{6}$ Department of Laboratory Medicine, Hunan Provincial People's Hospital, The First Affiliated Hospital of Hunan \\ Normal University, Changsha, China
}

Schizophrenia (SZ) is a debilitating and heterogeneous disease. We hypothesized that the oxytocin (OXT) system, inflammation and one-carbon metabolism would have a link with SZ. In this study, serum OXT, OXT receptor (OXTR), interleukin-6 (IL-6), high sensitivity CRP (hsCRP) and homocysteine (Hcy) levels were measured in 52 first-episode schizophrenia (FES) patients and 41 healthy controls (HC) from the Second Xiangya Hospital of Central South University. Meanwhile, the mRNA expressions of OXT and OXTR genes were determined by real-time quantitative PCR. Serum OXT and OXTR levels were significantly lower in FES patients $(518.96 \pm 22.22$ and $174.60 \pm 17.11 \mathrm{pg} / \mathrm{ml})$ than the HC group $(711.58 \pm 40.57$ and $252.15 \pm 20.62 \mathrm{pg} / \mathrm{ml})$. Serum IL-6 and hsCRP levels showed no difference between the two groups (1.82 $\pm 0.30 \mathrm{vs.} 1.69 \pm 0.36 \mathrm{pg} / \mathrm{ml}, 0.66(0.22,1.07)$ vs. $0.31(0.13,0.91) \mathrm{mg} / \mathrm{L})$, but serum Hcy levels were significantly higher in FES patients $(20.18 \pm 1.83$ vs. $15.24 \pm 0.82 \mu \mathrm{mol} / \mathrm{ml})$. The FES patients $(0.27 \pm 0.02$ and $0.20 \pm 0.02)$ have relatively higher mRNA expressions of OXT and OXTR genes than the HC group $(0.16 \pm 0.01$ and $0.14 \pm 0.01)$. In summary, our results suggested the possible function of the OXT system and Hcy in the pathogenesis of SZ.

Keywords: FES, OXT, OXTR, IL-6, hsCRP, Hcy

\section{INTRODUCTION}

Schizophrenia (SZ) is a debilitating and heterogeneous disease with unknown mechanism. Oxytocin (OXT) is a nonapeptide, known to be synthesized in the hypothalamus and released into the blood stream from the axon terminals of the posterior pituitary. Increasing evidence has shown that OXT might be the potential therapeutic target for SZ patients in animal and clinical case-control research $(1,2)$. Therefore, several randomized controlled trials (RCTs) have investigated the efficacy of OXT on improving positive symptoms, negative symptoms and cognitive deficits in SZ patients (3-6). Alterations of OXT levels are reported in several studies; however, the endogenous OXT levels were still conflicting in SZ patients with higher (7) and lower (8) amounts in plasma and tantamount levels in CSF (9) when compared with healthy controls (HC). OXT receptor (OXTR), a single seventransmembrane G-protein coupled receptor, is thought to mediate the actions of OXT. Meanwhile, the peripheral and central OXTR levels have only been scarcely reported. 
At the gene expression level, there are several studies suggesting that single nucleotide polymorphisms (SNPs) of OXT and OXTR genes were associated with symptom scores in SZ patients $(10,11)$. Furthermore, variants in OXTR were nominally associated with severity of overall symptoms as well as with the improvement of the positive symptoms (12). In recent research, Yang et al. reported relatively higher mRNA expression of OXT and OXTR genes in the peripheral blood lymphocytes (13). In a post-mortem study, there was decreased OXTR mRNA expression in the anterior prefrontal cortex and caudate nucleus (14). Together, these data suggest that alteration in the OXT system may underlie the pathogenesis of SZ.

Numerous studies have demonstrated that the immune system and inflammation might be involved in the pathophysiology of SZ $(15,16)$. Interleukin-6 (IL-6) is a pleiotropic cytokine synthesized by activated monocytes and Th2 lymphocytes and is one of the most frequently studied cytokines in SZ. IL-6 has been suggested to mediate the microglial-induced inflammatory response to neurogenesis (17). Previous data showed higher serum and cerebrospinal fluid (CSF) IL-6 levels in SZ patients and increased mRNA expression of IL-6 in post-mortem brain of SZ patients (18-20). High sensitivity CRP (hsCRP) is a nonspecific marker of inflammatory state and is mainly synthesized by hepatocytes in response to proinflammatory cytokines. It has been reported that elevated hsCRP levels were associated with increased risk of SZ in a case-control study (21). Additionally, the elevation of hsCRP was suppressed by the medical treatment for SZ with acute agitation (22).

Homocysteine (Hcy) is a sulfur-containing amino acid involved in the one-carbon metabolism of methionine cycle. Recently, an increase in Hcy levels has been reported in several neuropsychiatric disorders including depression (23), bipolar disorder (24) and SZ (25). Fan et al. reported significantly higher serum Hcy in firstepisode and drug-naïve SZ patients, which could be reduced after risperidone treatment (26). Furthermore, a positive correlation was found between plasma Hcy levels and scores of negative symptoms in SZ patients, but not with positive symptoms (27). It has also been estimated in a meta-analysis that a $5 \mu \mathrm{mol} / \mathrm{L}$ increase in plasma Hcy level may increase the risk of SZ by $70 \%$ (28).

Although the oxytocin (OXT) system, inflammation and one-carbon metabolism could have a link with SZ, some results were still conflicting. It was reported that antipsychotic treatment may influence OXT levels (29), but the exact mechanism is not known. Additionally, as far as we know, there is no report about the relationship of mRNA expression and serum levels of OXT and OXTR in the same patient. In animal experiments, OXT was decreased in older IL- $6^{-/}$mice (30), and Hcy was reported to increase OXTR expression (31). So, in this study, we determined the relative mRNA expression of OXT and OXTR genes in first-episode, unmedicated schizophrenia (FES) patients and HC. Meanwhile, the serum OXT, OXTR, IL-6, hsCRP and Hcy levels were measured.

\section{MATERIALS AND METHODS}

\section{Subjects}

A total of 52 FES patients were recruited from the Department of Psychiatry in the Second Xiangya Hospital of Central South
TABLE 1 | Demographic data for FES patients and HC.

\begin{tabular}{lccr}
\hline & FES (N = 52) & HC (N = 41) & P-value \\
\hline Gender (Male/Female) & $31 / 21$ & $23 / 18$ & 0.733 \\
Age (Mean \pm SD) & $20.71 \pm 4.62$ & $22.15 \pm 4.11$ & 0.104 \\
$\quad$ Male & $21.45 \pm 5.19$ & $22.91 \pm 3.75$ & \\
$\quad$ Female & $19.62 \pm 4.08$ & $21.17 \pm 4.20$ & \\
PANSS & & & \\
Total & $70.74 \pm 19.39$ & $/$ & \\
$\quad$ Positive & $20.26 \pm 5.35$ & $/$ & \\
$\quad$ Negative & $18.39 \pm 4.38$ & $/$ & \\
$\quad$ General & $32.09 \pm 10.01$ & & \\
\hline
\end{tabular}

University. These patients were diagnosed with FES by two senior psychiatrists according to the criteria of the Diagnostic and Statistical Manual of Mental Disorders, Fifth Edition (DSM$\mathrm{V})$. All these patients were required to sign an informed consent form and were not treated with any antipsychotic drugs for a month at least before the research. Patients with comorbid mental disorders, a history of traumatic brain injury or intellectual disability, or serious somatic diseases, pregnancy or breast feeding were excluded. Meanwhile, 41 age- and gender-matched healthy controls (HC) were enrolled from the health management center of the Second Xiangya Hospital. Demographic features of FES patients and HC group are demonstrated in Table 1.

This study was approved by the Ethics Committee of the Second Xiangya Hospital of Central South University. All the patients or their statutory guardians and $\mathrm{HC}$ were required to sign an informed consent form.

\section{Sample Collection}

Blood samples of 52 FES patients and 41 healthy controls were collected from each participant at 08:00 a.m. after overnight fasting. Serum was isolated after centrifuging at $3500 \mathrm{rpm}$ for $10 \mathrm{~min}$, and peripheral blood mononuclear cells (PBMCs) were isolated and stored at $-80^{\circ} \mathrm{C}$ until the biochemistry analysis or RNA was extracted without repeated freezing and thawing.

\section{Measurement of Serum OXT, OXTR, IL-6, Hcy and hsCRP Levels}

Serum OXT and OXTR as well as IL-6 levels were measured in duplicate by enzyme-linked immunosorbent assay (ELISA) using a comercially available kit (Cloud-Clone Corp). Serum Hcy and hsCRP were measured with latex enhanced immunoturbidimetric assay in a HITACHI 7600020 automatic biochemical analyzer.

\section{RNA Extraction and Real Time qPCR Analysis}

The RNA was extracted from PBMCs in a MagNA Pure LC2.0 Automatic extractor with a MagNA Pure LC Total Nucleic Acid Isolation Kit (Roche Diagnostics, IN, USA). The complementary DNA (cDNA) was synthesized after extracting the RNA of all samples. The expression levels of OXT and OXTR mRNA were measured using real-time quantitative PCR. The primers of OXT and OXTR genes as well as reference genes refer to Yang et al. (13). All reactions were completed in triplicates with the Roche 
LightCycler 480 (Roche) with the following cycling conditions (total reaction volume $=20 \mu \mathrm{l}$ ): $95^{\circ} \mathrm{C}$ for 10 minutes, followed by 40 cycles of denaturation at $95^{\circ} \mathrm{C}(10$ seconds $)$, annealing at $60^{\circ} \mathrm{C}$ (10 seconds) and extension at $72^{\circ} \mathrm{C}$ (20 seconds). The deltaCt $(\Delta \mathrm{Ct})$ method was used to perform relative quantification, and the housekeeping gene $\beta$-actin was used as the reference gene.

\section{Statistical Analysis}

SPSS v21.0 (IBM, USA) statistical software was used to perform statistical analysis. Data were presented as mean \pm standard error (SE) for normal distribution variables (at Kolmogorov-Smirnov test) and median (quartile range) for non-normal distribution variables. Comparisons between two groups were analyzed with unpaired Student's t-test or Mann-Whitney U-test as appropriate. $P<0.05$ was considered statistically significant.

\section{RESULTS}

\section{Serum OXT, OXTR, IL-6, hsCRP and Hcy Levels in HC Group and FES Patients}

As we can see from Figure 1, serum OXT and OXTR levels in HC group (711.58 \pm 40.57 and $252.15 \pm 20.62 \mathrm{pg} / \mathrm{ml}$, respectively) were significantly higher $(\mathrm{t}=-4.164$ and $\mathrm{t}=-2.894, P=0.000$ and $P=0.007$, respectively) than in FES patients $(518.96 \pm 22.22$ and $174.60 \pm 17.11 \mathrm{pg} / \mathrm{ml}$, respectively). Serum IL-6 and hsCRP levels in HC group $(1.69 \pm 0.36 \mathrm{pg} / \mathrm{ml}$ and $0.31(0.13,0.91) \mathrm{mg} / \mathrm{L})$ showed no difference $(\mathrm{t}=0.283$ and $\mathrm{Z}=-1.218, P=0.778, P=$ $0.223)$ with FES patients $(1.82 \pm 0.30 \mathrm{pg} / \mathrm{ml}$ and $0.66(0.22,1.07)$ $\mathrm{mg} / \mathrm{L})$. Meanwhile, serum Hcy levels were significantly lower $(\mathrm{t}=2.459, P=0.020)$ in $\mathrm{HC}$ group $(15.24 \pm 0.82 \mu \mathrm{mol} / \mathrm{ml})$ than in FES patients $(20.18 \pm 1.83 \mu \mathrm{mol} / \mathrm{ml})$.

\section{mRNA Expressions of OXT and OXTR Genes in HC Group and FES Patients}

The mRNA expressions of OXT and OXTR genes were semiquantitative and performed with real-time PCR. The expressions of OXT and OXTR mRNA were significantly lower $(P=0.000$ and $P=0.007$, respectively) in the $\mathrm{HC}$ group $(0.16 \pm 0.01$ and $0.14 \pm 0.01$, respectively) than in FES patients $(0.27 \pm 0.02$ and $0.20 \pm 0.02$, respectively). These results were shown in Figure 2.

\section{DISCUSSION}

The etiology of schizophrenia is still not known with certainty. One possible breakthrough is the OXT system, which presented potential therapeutic efficacy similar to antipsychotic drugs (APDs).
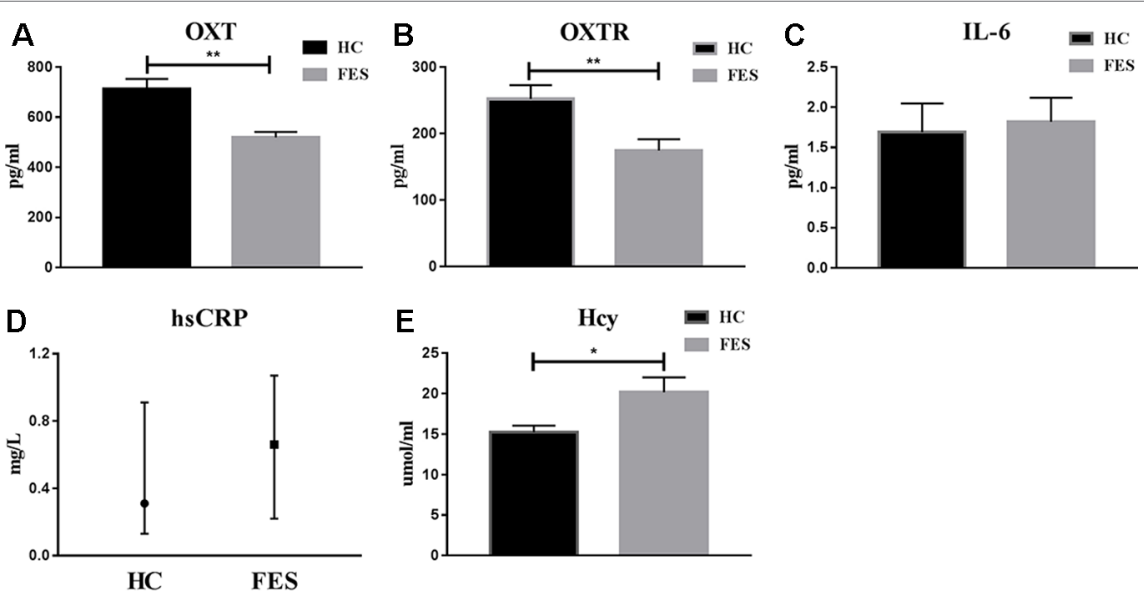

FIGURE 1 | Serum OXT, OXTR, IL-6, hsCRP and Hcy levels in HC group and FES patients. * means $P<0.05$, ${ }^{*}$ means $P<0.01$.
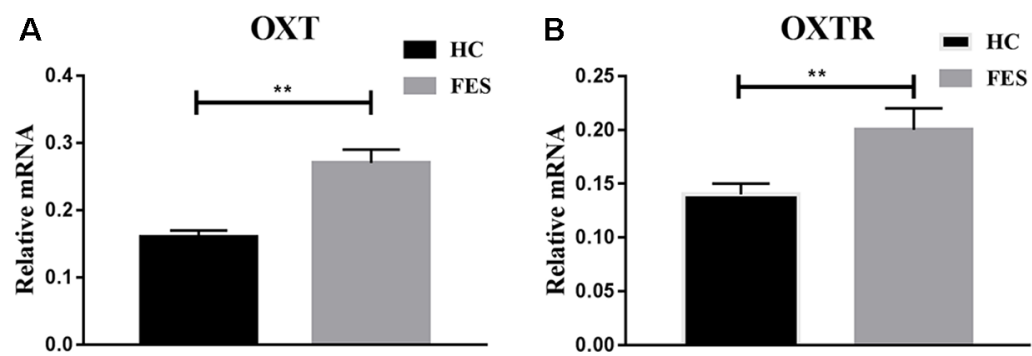

FIGURE 2 | mRNA expressions of OXT and OXTR genes in HC groups and FES patients. ${ }^{*}$ means $P<0.05,{ }^{* *}$ means $P<0.01$. 
In this study, we found that serum OXT and OXTR levels were significantly lower in FES patients than in the HC group. This is consistent with two recent reports indicating diminished plasma OXT levels in SZ patients $(8,32)$. Based on these results, a pile of RCTs have investigated the efficacy of intranasal OXT on improving positive symptoms, negative symptoms and cognitive deficits in SZ patients (33-36). Although there is a minority of negative results $(37,38)$, most of these RCTs showed significant improvement in clinical symptoms of SZ patients using doses ranging from 10 to $40 \mathrm{IU}$ for single-dose or twice daily (1). Meanwhile, we found that the mRNA expression of OXT and OXTR in FES patients was significantly higher than in the HC group in the peripheral blood lymphocytes, which is in accordance with a previous study by Yang et al. (13). However, Uhrig et al. reported downregulation of OXTR mRNA in the temporal cortex and a decrease in receptor binding in the vermis (14), but OXT mRNA expression in the brain areas has been scarcely reported. Thus, the relationship between peripheral and central mRNA expression deserves further exploration. It is worth noting that the increased serum OXT and OXTR levels were contrary to the downregulation of mRNA expression of OXT and OXTR genes. We speculate that the transcription of OXT and OXTR genes is working normally, but with the disrupted interpretation, transportation and release of OXT and OXTR proteins. Another possibility is that the elevated serum Hcy levels contributed to the increased OXT and OXTR.

Another goal of the study was to explore whether there are disturbances in the inflammation system of SZ patients. It has long been speculated that immuno-inflammatory disorders are associated with SZ. A meta-analysis performed by Miller et al. showed that some cytokine alterations (including IL-6) were significantly associated with SZ (39). HsCRP is one of the most frequently used nonspecific markers of inflammation state mediated by proinflammatory cytokines such as IL-6. In this study, our results showed that serum IL- 6 and hsCRP levels in FES patients were slightly higher than those in the HC group with no significant difference. SZ is a heterogeneous disease with multiple pathogenic factors. Although the OXT system is abnormal in FES patients, the immuno-inflammatory indicators are normal in this study, suggesting that immune disorders might not be the main contributor of SZ. Despite the inconsistency of our observation with most of the previous studies, there are some reports indicating no difference between SZ patients and HC groups in IL-6 levels (40). Most studies reported higher serum hsCRP levels in SZ patients than HC groups $(15,41)$, which is contrary to our results. One possible explanation is that APD treatment raises serum hsCRP levels in SZ patients (42). Another speculation is that the OXT system might not obviously be related to inflammation in humans despite the positive effect of IL-6 on OXT secretion in mice (30).

\section{REFERENCES}

1. Feifel D, Shilling PD, MacDonald K. A review of oxytocin's effects on the positive, negative, and cognitive domains of schizophrenia. Biol Psychiatry (2016) 79:222-33. doi: 10.1016/j.biopsych.2015.07.025

2. Guoynes CD, Simmons TC, Downing GM, Jacob S, Solomon M, Bales KL. Chronic intranasal oxytocin has dose-dependent effects on
Hcy alteration has been shown to be associated with many psychiatric disorders, including SZ. In this study, we found that serum Hcy levels were significantly higher in FES patients than in the HC group, which is in agreement with the majority of reported results $(26,43,44)$. It was reported that more severe negative symptoms are associated with higher Hcy level, and there is a negative correlation between duration of untreated psychosis (DUP) and Hcy level (25). Usually, the elevation of serum Hcy level is considered to be a pathogenic factor for the development of SZ. However, the exact mechanism of increased serum Hcy levels in SZ patients is not definite, and it is speculated that poor nutrition, tobacco consumption, alcohol, coffee and polymorphisms in the enzymes of Hcy metabolism can all contribute to elevated Hcy levels $(45,46)$. Therefore, the onecarbon metabolism in FES patients seems to be a future direction to elucidate the psychopathology of SZ. Future research should focus on the expression of these parameters in the brain nuclei and finding out whether OXT administration, anti-inflammatory treatment and lowering serum Hcy levels could improve the symptoms of schizophrenia patients.

In summary, we found that serum OXT and OXTR levels were significantly lower in FES patients, while the mRNA expression of OXT and OXTR genes were significantly higher in FES patients. The serum Hcy levels were also significantly higher. These results suggested that the dysfunction of the OXT system and Hcy metabolism underlay the pathogenesis of SZ, and the negative results of inflammatory indicators must be interpreted with caution considering the moderate sample size.

\section{AUTHOR CONTRIBUTIONS}

$\mathrm{CL}$ designed the study. $\mathrm{KH}$ and $\mathrm{XZ}$ acquired the data, which $\mathrm{HT}$ and XY analyzed. YL wrote the article, which all authors reviewed and approved for publication.

\section{FUNDING}

This work was supported by the National Natural Science Foundation of China (No. 81771448); the Hunan Provincial Science and Technology Bureau Foundation of China (No. 2017SK50509); and the Hunan Provincial Natural Science Foundation of China (Nos. 2015JJ4069, 2018JJ2580, 2018JJ3387).

\section{ACKNOWLEDGEMENT}

We are grateful to all the schizophrenia patients and healthy controls who participated in this study. 
4. Dagani J, Sisti D, Abelli M, Di Paolo L, Pini S, Raimondi S, et al. Do we need oxytocin to treat schizophrenia? A randomized clinical trial. Schizophr Res (2016) 172:158-64. doi: 10.1016/j.schres.2016.02.011

5. Cacciotti-Saija C, Langdon R, Ward PB, Hickie IB, Scott EM, Naismith SL, et al. A double-blind randomized controlled trial of oxytocin nasal spray and social cognition training for young people with early psychosis. Schizophr Bull (2015) 41:483-93. doi: 10.1093/schbul/sbu094

6. Gibson CM, Penn DL, Smedley KL, Leserman J, Elliott T, Pedersen CA. A pilot six-week randomized controlled trial of oxytocin on social cognition and social skills in schizophrenia. Schizophr Res (2014) 156:261-5. doi: 10.1016/j.schres.2014.04.009

7. Walss-Bass C, Fernandes JM, Roberts DL, Service H, Velligan D. Differential correlations between plasma oxytocin and social cognitive capacity and bias in schizophrenia. Schizophr Res (2013) 147:387-92. doi: 10.1016/j. schres.2013.04.003

8. Jobst A, Dehning S, Ruf S, Rujescu D, Muller DJ, Gallinat J. Oxytocin and vasopressin levels are decreased in the plasma of male schizophrenia patients. Acta Neuropsychiatr (2014) 26:347-55. doi: 10.3109/15622975. 2012.677547

9. Sasayama D, Hattori K, Teraishi T, Hori H, Ota M, Yoshida S, et al. Negative correlation between cerebrospinal fluid oxytocin levels and negative symptoms of male patients with schizophrenia. Schizophr Res (2012) 139:201-6. doi: 10.1016/j.schres.2012.06.016

10. Montag C, Brockmann EM, Bayerl M, Rujescu D, Muller DJ, Gallinat J, et al. Oxytocin and oxytocin receptor gene polymorphisms and risk for schizophrenia: a case-control study. World J Biol Psychiatry (2013) 14:500-8. doi: 10.3109/15622975.2012.677547

11. Teltsh O, Kanyas-Sarner K, Rigbi A, Greenbaum L, Lerer B, Kohn Y. Oxytocin and vasopressin genes are significantly associated with schizophrenia in a large Arab-Israeli pedigree. Int J Neuropsychopharmacol (2012) 15:309-19. doi: $10.1017 /$ S1461145711001374

12. Souza RP, de Luca V, Meltzer HY, Lieberman JA, Kennedy JL. Schizophrenia severity and clozapine treatment outcome association with oxytocinergic genes. Int J Neuropsychopharmacol (2010) 13:793-8. doi: 10.1017/S14611 45710000167

13. Yang $X$, Tang $Y$, Wei $Q$, Lang $B$, Tao $H$, Zhang $X$, et al. Up-regulated expression of oxytocin mRNA in peripheral blood lymphocytes from firstepisode schizophrenia patients. Oncotarget (2017) 8:78882-9. doi: 10.18632/ oncotarget. 20252

14. Uhrig S, Hirth N, Broccoli L, von Wilmsdorff M, Bauer M, Sommer C, et al. Reduced oxytocin receptor gene expression and binding sites in different brain regions in schizophrenia: a post-mortem study. Schizophr Res (2016) 177:59-66. doi: 10.1016/j.schres.2016.04.019

15. Zhang Q, Hong W, Li H, Peng F, Wang F, Li N, et al. Increased ratio of high sensitivity C-reactive protein to interleukin-10 as a potential peripheral biomarker of schizophrenia and aggression. Int J Psychophysiol (2017) 114:9-15. doi: 10.1016/j.ijpsycho.2017.02.001

16. de Witte L, Tomasik J, Schwarz E, Guest PC, Rahmoune H, Kahn RS, et al. Cytokine alterations in first-episode schizophrenia patients before and after antipsychotic treatment. Schizophr Res (2014) 154:23-9. doi: 10.1016/j. schres.2014.02.005

17. Na KS, Jung HY, Kim YK. The role of pro-inflammatory cytokines in the neuroinflammation and neurogenesis of schizophrenia. Prog Neuropsychopharmacol Biol Psychiatry (2014) 48:277-86. doi: 10.1016/j. pnpbp.2012.10.022

18. Schwieler L, Larsson MK, Skogh E, Kegel ME, Orhan F, Abdelmoaty S, et al. Increased levels of IL-6 in the cerebrospinal fluid of patients with chronic schizophrenia-significance for activation of the kynurenine pathway. J Psychiatry Neurosci (2015) 40:126-33. doi: 10.1503/jpn.140126

19. An HM, Tan YL, Shi J, Wang ZR, Soars JC, Wu JQ, et al. Altered IL-2, IL-6 and IL-8 serum levels in schizophrenia patients with tardive dyskinesia. Schizophr Res (2015) 162:261-8. doi: 10.1016/j.schres.2014.12.037

20. Fillman SG, Cloonan N, Catts VS, Miller LC, Wong J, McCrossin T, et al. Increased inflammatory markers identified in the dorsolateral prefrontal cortex of individuals with schizophrenia. Mol Psychiatry (2013) 18:206-14. doi: $10.1038 / \mathrm{mp} .2012 .110$

21. Joseph J, Depp C, Martin AS, Daly RE, Glorioso DK, Palmer BW, et al. Associations of high sensitivity C-reactive protein levels in schizophrenia and comparison groups. Schizophr Res (2015) 168:456-60. doi: 10.1016/j. schres.2015.08.019

22. Pan S, Tan Y, Yao S, Zhao X, Xiong J. Serum high-sensitivity C-reactive protein: a delicate sentinel elevated in drug-free acutely agitated patients with schizophrenia. Psychiatry Res (2016) 246:89-94. doi: 10.1016/j. psychres.2016.09.033

23. Nabi H, Bochud M, Glaus J, Lasserre AM, Waeber G, Vollenweider P, et al. Association of serum homocysteine with major depressive disorder: results from a large population-based study. Psychoneuroendocrinology (2013) 38:2309-18. doi: 10.1016/j.psyneuen.2013.04.018

24. Salagre E, Vizuete AF, Leite M, Brownstein DJ, McGuinness A, Jacka F, et al. Homocysteine as a peripheral biomarker in bipolar disorder: a metaanalysis. Eur Psychiatry (2017) 43:81-91. doi: 10.1016/j.eurpsy.2017.02.482

25. Misiak B, Frydecka D, Slezak R, Piotrowski P, Kiejna A. Elevated homocysteine level in first-episode schizophrenia patients-the relevance of family history of schizophrenia and lifetime diagnosis of cannabis abuse. Metab Brain Dis (2014) 29:661-70. doi: 10.1007/s11011-014-9534-3

26. Fan N, Tan Y, Yang F, Tian L, Chen S, Li J, et al. Effect of risperidone on serum homocysteine levels in first-episode, drug-naive patients with schizophrenia. Neurosci Lett (2017) 650:168-73. doi: 10.1016/j.neulet.2017.04.025

27. Petronijevic ND, Radonjic NV, Ivkovic MD, Marinkovic D, Piperski VD, Duricic BM, et al. Plasma homocysteine levels in young male patients in the exacerbation and remission phase of schizophrenia. Prog Neuropsychopharmacol Biol Psychiatry (2008) 32:1921-6. doi: 10.1016/j. pnpbp.2008.09.009

28. Muntjewerff JW, Kahn RS, Blom HJ, den Heijer M. Homocysteine, methylenetetrahydrofolate reductase and risk of schizophrenia: a metaanalysis. Mol Psychiatry (2006) 11:143-9. doi: 10.1038/sj.mp.4001746

29. Uvnas-Moberg K, Alster P, Svensson TH. Amperozide and clozapine but not haloperidol or raclopride increase the secretion of oxytocin in rats. Psychopharmacology (Berl) (1992) 109:473-6. doi: 10.1007/bf02247726

30. Benrick A, Schele E, Pinnock SB, Wernstedt-Asterholm I, Dickson SL, Karlsson-Lindahl L, et al. Interleukin-6 gene knockout influences energy balance regulating peptides in the hypothalamic paraventricular and supraoptic nuclei. J Neuroendocrinol (2009) 21:620-8. doi: 10.1111/j.1365-2826.2009.01879.x

31. Sonne SR, Bhalla VK, Barman SA, White RE, Zhu S, Newman TM, et al. Hyperhomocysteinemia is detrimental to pregnancy in mice and is associated with preterm birth. Biochim Biophys Acta (2013) 1832:1149-58. doi: 10.1016/j.bbadis.2013.04.006

32. Goldman M, Marlow-O’Connor M, Torres I, Carter CS. Diminished plasma oxytocin in schizophrenic patients with neuroendocrine dysfunction and emotional deficits. Schizophr Res (2008) 98:247-55. doi: 10.1016/j. schres.2007.09.019

33. Burkner PC, Williams DR, Simmons TC, Woolley JD. Intranasal oxytocin may improve high-level social cognition in schizophrenia, but not social cognition or neurocognition in general: a multilevel bayesian metaanalysis. Schizophr Bull (2017) 43:1291-1303. doi: 10.1093/schbul/ sbx053

34. Buchanan RW, Kelly DL, Weiner E, Gold JM, Strauss GP, Koola MM, et al. A randomized clinical trial of oxytocin or galantamine for the treatment of negative symptoms and cognitive impairments in people with schizophrenia. J Clin Psychopharmacol (2017) 37:394-400. doi: 10.1097/ JCP.0000000000000720

35. Lee MR, Wehring HJ, McMahon RP, Liu F, Linthicum J, Verbalis JG, et al. Relationship of plasma oxytocin levels to baseline symptoms and symptom changes during three weeks of daily oxytocin administration in people with schizophrenia. Schizophr Res (2016) 172:165-8. doi: 10.1016/j. schres.2016.02.014

36. Lee MR, Wehring HJ, McMahon RP, Linthicum J, Cascella N, Liu F, et al. Effects of adjunctive intranasal oxytocin on olfactory identification and clinical symptoms in schizophrenia: results from a randomized double blind placebo controlled pilot study. Schizophr Res (2013) 145:110-5. doi: 10.1016/j.schres.2013.01.001

37. Jarskog LF, Pedersen CA, Johnson JL, Hamer RM, Rau SW, Elliott T, et al. A 12-week randomized controlled trial of twice-daily intranasal oxytocin for social cognitive deficits in people with schizophrenia. Schizophr Res (2017) 185:88-95. doi: 10.1016/j.schres.2017.01.008 
38. Busnelli M, Dagani J, de Girolamo G, Balestrieri M, Pini S, Saviotti FM, et al. Unaltered oxytocin and vasopressin plasma levels in patients with schizophrenia after 4 months of daily treatment with intranasal oxytocin. J Neuroendocrinol (2016) 28. doi: 10.1111/jne.12359

39. Miller BJ, Buckley P, Seabolt W, Mellor A, Kirkpatrick B. Meta-analysis of cytokine alterations in schizophrenia: clinical status and antipsychotic effects. Biol Psychiatry (2011) 70:663-71. doi: 10.1016/j.biopsych.2011.04.013

40. Zakharyan R, Petrek M, Arakelyan A, Mrazek F, Atshemyan S, Boyajyan A. Interleukin-6 promoter polymorphism and plasma levels in patients with schizophrenia. Tissue Antigens (2012) 80:136-42. doi: 10.1111/j. 1399-0039.2012.01886.x

41. Lin CC, Chang CM, Liu CY, Huang TL. Increased high-sensitivity C-reactive protein levels in Taiwanese schizophrenic patients. Asia Pac Psychiatry (2013) 5:E58-E63. doi: 10.1111/appy.12078

42. Loffler S, Loffler-Ensgraber M, Fehsel K, Klimke A. Clozapine therapy raises serum concentrations of high sensitive C-reactive protein in schizophrenic patients. Int Clin Psychopharmacol (2010) 25:101-6. doi: 10.1097/YIC. 0b013e32833643fd

43. Song X, Fan X, Li X, Kennedy D, Pang L, Quan M, et al. Serum levels of BDNF, folate and homocysteine: in relation to hippocampal volume and psychopathology in drug naive, first episode schizophrenia. Schizophr Res (2014) 159:51-5. doi: 10.1016/j.schres.2014.07.033
44. Moustafa AA, Hewedi DH, Eissa AM, Frydecka D, Misiak B. Homocysteine levels in schizophrenia and affective disorders-focus on cognition. Front Behav Neurosci (2014) 8:343. doi: 10.3389/fnbeh.2014.00343

45. Gultepe M, Ozcan O, Avsar K, Cetin M, Ozdemir AS, Gok M. Urine methylmalonic acid measurements for the assessment of cobalamin deficiency related to neuropsychiatric disorders. Clin Biochem (2003) 36:275-82. doi: 10.1016/s0009-9120(03)00033-x

46. Schneede J, Refsum H, Ueland PM. Biological and environmental determinants of plasma homocysteine. Semin Thromb Hemost (2000) 26:263-79. doi: 10.1055/s-2000-8471

Conflict of Interest Statement: The authors declare that the research was conducted in the absence of any commercial or financial relationships that could be construed as a potential conflict of interest.

Copyright (c) 2019 Liu, Tao, Yang, Huang, Zhang and Li. This is an open-access article distributed under the terms of the Creative Commons Attribution License (CC $B Y)$. The use, distribution or reproduction in other forums is permitted, provided the original author(s) and the copyright owner(s) are credited and that the original publication in this journal is cited, in accordance with accepted academic practice. No use, distribution or reproduction is permitted which does not comply with these terms. 